Article

\title{
Concrete Compressive Strength under Changing Environmental Conditions during Placement Processes
}

\author{
Andrzej Ambroziak * (D) and Patryk Ziolkowski \\ Faculty of Civil and Environmental Engineering, Gdansk University of Technology, Gabriela Narutowicza 11/12, \\ 80-233 Gdansk, Poland; patziolk@pg.edu.pl \\ * Correspondence: ambrozan@pg.edu.pl; Tel.: +48-(58)-347-2447
}

Received: 20 September 2020; Accepted: 12 October 2020; Published: 14 October 2020

check for updates

\begin{abstract}
The technological process of concrete production consists of several parts, including concrete mix design, concrete mix production, transportation of fresh concrete mix to a construction site, placement in concrete framework, and curing. Proper execution of these steps provides good quality concrete. Some factors can disturb the technological process, mainly temperature and excessive precipitation. Changing daily temperature and rainfall during fabrication, transportation, and placement can shape not only the properties of the concrete mix but also the compressive strength of hardened concrete. In this paper, we tried to answer the question of how temperature and precipitation affect concrete production. The scope of this study was to determine the change of compressive strength of the hardened concrete in a specific period for selected concrete mix recipes, taking into account changing daily temperature and precipitation magnitude. The investigated concrete mixes concrete compressive strength beyond that of the concrete grade, termed "concrete superstrength". This concrete post limiting behaviour of concrete is also discussed.
\end{abstract}

Keywords: concrete mix; concrete mix design; concrete durability; concrete; uniaxial compression tensile test

\section{Introduction}

One of the most widespread and accessible construction materials used in civil engineering is concrete. The significant uses of concrete are dams, residential and commercial buildings, roads and driveways, marine constructions, culverts and sewers, foundations, concrete bridges, fences, and many more. Many standards specify basic requirements for the design of structural concrete, such as the Eurocodes in Europe (EN 1992-1-1 [1]), and American Concrete Institute Standards in the United States (ACI 318-19 [2]). Usually, the designer adopts the mechanical properties of concrete for a specified load and planed construction life-cycle according to regional standards or specifications. The manufacturer of the concrete mix has to fulfil requirements for concrete properties following the designer's recommendations and the standard provisions. The mechanical, chemical, and physical properties of concrete depend on the composition and proportions of the individual components of the concrete mix. Several parameters characterise a fresh ready-mixed concrete delivered by the producer, which are: consistency, cement content and water/cement ratio, air content, and maximum aggregate size [3,4]. Factors characterising liquid concrete are different from those in a solid-state [5,6]. Hardened concrete has to achieve specified compressive strength class, density, resistance to water penetration, and others [7]. The ultimate durability of concrete depends to a large extent on the contractor that is responsible for the placement and curing process, whose activity is also described by normal provisions and good practices [8]. Concrete placement is an essential part of the technological process of concrete production and is preceded by the following steps: concrete mix 
design [9-12], concrete mix fabrication, and transportation to the construction site. Transportation and placement are especially vulnerable to environmental conditions, such as temperature and precipitation. Adverse environmental conditions at these stages can affect the properties of hardened concrete [13-15].

One of the first studies of concrete produced in different environmental conditions is the work of W.H. Price from 1951 [16]. W.H. Price tested the effects of mix proportions, types of cement, and admixtures, which accelerate curing. J.I. Escalante-Garcia and his team brought a significant contribution to studying concrete in different environmental conditions. They published several papers on that issue which we would like to focus on [17-19]. J.I. Escalante-Garcia et al. [17] observed that initially, increased temperature accelerated the hydration of the four major anhydrous phases present in two Mexican Portland cements. However, in the longer term, a reduced degree of hydration was observed for the alite and ferrite phases, accompanied by decreased compressive strength and increased apparent porosity. In their second study [18], they observed the degree of hydration is reduced at $60^{\circ} \mathrm{C}$ in comparison to that at $10^{\circ} \mathrm{C}$; what is more, replacement materials such as volcanic ash transformed hydration patterns for each cement phase. Hydration of alite, ferrite, and $\mathrm{C}_{3} \mathrm{~A}$ (Tricalcium Aluminate) was faster, and there were some differences for different replacement materials. The hydration of belite was slowed down at higher temperatures by the pulverised fuel ash admixture, but augmented by volcanic ash. The last study [19] focused on the development of the microstructure and compressive strength of three blended cement pastes in temperatures ranging from 10 to $60^{\circ} \mathrm{C}$. A higher temperature during hydration leads to higher early concrete strength, but full compressive strength seems to be reduced in comparison with cement hydrated at a lower temperature.

J. Komonen et al. [20] studied the effects of high temperature on the residual properties of plain and polypropylene fibre reinforced Portland cement paste. According to J.J. Thomas et al. [21], the temperature is a crucial variable, which influences both the hydration process and the properties of the hardened concrete. Concrete initially gains strength more rapidly when cured at elevated temperatures, but the ultimate strength is lower and permeability increases. Very useful for our considerations were studies of concrete behaviour in hot climates by K.A. Soudki et al. [22]. They found out that high temperatures cause increased water demand, loss in rates of slump and setting, and also develop a higher tendency for crazing and plastic cracking. They concluded that high temperatures could reduce serviceability and deteriorate the mechanical properties of concrete. Another interesting work is a study of G. Cygan et al. [23]. They studied the rheological properties of self-compacting concrete in various temperatures. G. Cygan et al. [23] proved that increased temperature accelerates the hydration process and cause the workability loss. At the same time, it also produces more ettringite, which adsorbs superplasticisers. They also found out that the efficiency of a superplasticiser depends on temperature.

In our research, we aimed to investigate the impacts of changing temperature and precipitation during the production and transport stages on concrete compressive strength. The parameters we followed were the mean daily compressive strength of concrete, the composition and features of the concrete mix, the average daily air temperature, and the daily rainfall. The problem of excessive compressive strength beyond that of the concrete grade is also discussed. The concrete that we tested was both produced and transported to a construction site located in Gdańsk, Poland.

\section{Materials and Methods}

\subsection{Concrete Mixing and Fabrication of Specimens}

In the EU Member States, the current norm is the concrete standard EN 206 [24] (non-harmonised EN-standard) with various national annexes that specifies all issues related to the technological process of concrete, such as certification, handling, production, quality control, and properties of fresh and hardened concrete. We investigated three types of concrete mixes named CM_A, CM_Aw, and CM_B that are based on CEM I (Portland cement; see EN 197-1 standard [25] and [26]). In Table 1, we present the mix proportions used for the laboratory tests. Two concrete mixes CM_A and CM_Aw were 
concrete grade C30/37 (according to EN 206 standard [24]) and CM_B mix was concrete grade C50/60. The minimum characteristic cubical strength $\left(\mathrm{f}_{\mathrm{ck}, \text { cube }}\right)$ for $\mathrm{C} 30 / 37$ concrete grade is $37 \mathrm{MPa}\left(\mathrm{N} / \mathrm{mm}^{2}\right)$ and for $\mathrm{C} 50 / 60$ concrete grade is $60 \mathrm{MPa}\left(\mathrm{N} / \mathrm{mm}^{2}\right)$. The characteristic compressive strength is specified at 28 days on concrete cubical samples with dimensions equal to $150 \mathrm{~mm}\left(\mathrm{f}_{\mathrm{ck}, \mathrm{cube}}\right)$. There is also the minimum characteristic cylindrical strength $\left(f_{c k, c y l}\right)$, which for $\mathrm{C} 30 / 37$ concrete grade is $30 \mathrm{MPa}$ $\left(\mathrm{N} / \mathrm{mm}^{2}\right)$, and for $\mathrm{C} 50 / 60$ concrete grade is $50 \mathrm{MPa}\left(\mathrm{N} / \mathrm{mm}^{2}\right)$. We adopted an S3 fresh concrete consistency class (with a slump from 100 to $150 \mathrm{~mm}$ ) and a maximum size of aggregate $16 \mathrm{~mm}$ according to EN 206 [24] for all investigated concrete mixes. CM_A and CM_Aw concrete mixes have similar amounts of standard Portland cement, aggregates, and type II admixtures (fly ash). The main difference between these mixes lies in the presence of additional admixtures (amounts and types are in Table 1). CM_B concrete mix had much more of CEM I cement compared to the other mixes. CM_B concrete mix alongside with water-reducers and plasticisers also has set-retarding chemical admixtures to extend built-in time. The concrete mixes had slightly varied density from $2322 \mathrm{~kg} / \mathrm{m}^{3}$ to $2397 \mathrm{~kg} / \mathrm{m}^{3}$ (see Table 1) and could be classified as normal density concrete grade (dry density from 2000 to $2600 \mathrm{~kg} / \mathrm{m}^{3}$ according to EN 206 [24] or from 2160 to $2560 \mathrm{~kg} / \mathrm{m}^{3}$ according to ACI 318-19 [2]).

Table 1. Concrete mix recipe data.

\begin{tabular}{rccc}
\hline Concrete Mix Type & CM_A & CM_Aw & CM_B \\
\hline Designed compressive strength class [MPa], according to [24] & C30/37 & C30/37 & C50/60 \\
Slump class [-], according to [24] & S3 & S3 & S3 \\
Concrete mix density [kg/m $\left.\mathrm{m}^{3}\right]$ & 2322 & 2328 & 2397 \\
Maximum size of aggregate [mm] & 16 & 16 & 16 \\
CEM I-Portland cement [kg], according to [25] & 300 & 310 & 410 \\
Type II addition (fly ash) [kg], according to [24] & 70 & 65 & 40 \\
Fine aggregate (sand) [kg] & 640 & 640 & 600 \\
Coarse aggregate 1 [kg] & 480 & 500 & 520 \\
Coarse aggregate 2 [kg] & 650 & 650 & 670 \\
Water reducing and plasticising admixture [kg] & 1.95 & - & 2.67 \\
Water reducing, plasticising and accelerating hardening admixture [kg] & - & 3.1 & - \\
Set-retarding, water-reducing and plasticising admixture [kg] & - & - & 0.82 \\
Water [1] & 180 & 160 & 153 \\
\hline
\end{tabular}

The ready-mixed concrete that we studied was delivered in a fresh state by the producer and used in the construction of an office building. Fabrication of specimens took place at a construction site in Gdansk (Northern Poland) directly before concrete placement (on average about $15 \mathrm{~min}$ after delivery) from January 2016 to October 2016; see Table 2. During the winter, the temperature of fresh concrete was not less than $+5{ }^{\circ} \mathrm{C}$ at the time of delivery. We have observed that the contractor maintains high quality concrete curing conditions according to EN 13670 [8] standard. We assume that the concrete producer also maintains high-quality products since his manufacturing facility is fully automated and computer-controlled. Each batch of fresh concrete mix supplied by the manufacturer was verified by uniaxial compression laboratory tests, which verified the mechanical properties of hardened concrete. Our standard cube concrete samples $15 \times 15 \times 15 \mathrm{~cm}$ in the mould were stored for one day at a temperature of $20 \pm 5^{\circ} \mathrm{C}$ while being protected against shock, vibrations, and dehydration. After removal from the mould, the concrete specimens were cured in water at temperature $20 \pm 2{ }^{\circ} \mathrm{C}$, as described in PN-EN 12390-2 [27] standard. Three or four cubical samples for each new daily batch of fresh concrete type mixes were prepared. In the investigated period, the CM_A, CM_Aw, and CM_B mixes were used in building site after 141, 40, and 50 days, respectively. The total number of prepared cores samples was 482 for the CM_A mix, 152 for the CM_Aw mix, and 152 for the CM_B mix; see Table 2. Strength tests of concrete samples were performed after 28 days and were used to confirm the designed concrete grades. The value of compressive strength can be used to estimate the tensile and flexural strength using standard formulas; see, e.g., [28]. 
Table 2. The period of specimen fabrication.

\begin{tabular}{cccc}
\hline Concrete Mix Type & Time Period & $\begin{array}{c}\text { Days Number of } \\
\text { Applicability Concrete Mix }\end{array}$ & $\begin{array}{c}\text { Total Number of } \\
\text { Concrete Samples }\end{array}$ \\
\hline CM_A & from 2016-01-22 to 2016-02-24 & 141 & 482 \\
CM_Aw & from 2016-04-05 to 2016-10-04 & 40 & 152 \\
CM_B & from 2016-01-30 to 2016-05-05 $2016-02-25$ to 2016-05-04 & 50 & 152 \\
\hline
\end{tabular}

\subsection{Concrete Superstrength}

Concrete superstrength is excessive compressive strength beyond that designed for the concrete grade. In the EN 206 standard [24] and other concrete standards, the upper limit of compressive strength for a certain concrete grade is not defined. The conformity criterion for the specification of concrete grade only specifies requirements for minimal compressive strength of concrete. Generally, the concrete manufacturer, to meet the conditions of the designed concrete, slightly overstates the designed concrete grade of the ready-mix concrete by about $5 \mathrm{MPa}$, to have a surplus for built-in concrete in the structure due to threat of not fulfilling the guaranteed concrete compressive strength, which would burden the manufacturer with additional costs. Some specifications for ready-mixed concrete contain a restriction of limit upper compressive strength. According to the "concrete post limiting behaviour" concept described by Jasiczak J. [29], the upper limit of compressive strength (ULCS) for the strength of the built-in concrete construction that does not exceed more than $25 \%$ of the designed one can be specified as:

$$
U L C S=1.25 \cdot \overline{f_{N}}[\mathrm{MPa}],
$$

where $\overline{f_{N}}$ is a normative average defined as:

$$
\overline{f_{N}}=f_{c k}+1.96 \cdot \sigma[\mathrm{MPa}],
$$

where $\sigma$ is a normative value of standard deviation and it is equal to $\sigma=5.4 \mathrm{MPa}$. According to Eurocode 2 [1], the normative value of standard deviation can be derived as follows:

$$
f_{c m}-f_{c k} \leq 1.48 \cdot \sigma \rightarrow 8 \leq 1.48 \cdot \sigma \rightarrow \sigma=8 / 1.48=5.4
$$

The value 1.96 from Equation (3) is associated with the assumption of the double-sided tolerance range [29].

The excessive compressive strength beyond that of the concrete grade may have negative outcomes for some types of structural elements. Based on this concept, it is possible to evaluate the phenomenon of the concrete superstrength that occurred in the investigated concrete mixes.

\subsection{Meteorological Data}

We took meteorological data from the Gdansk Rebiechowo station (number code: 254180090) operated by the Polish Institute of Meteorology and Water Management-National Research Institute [30] in Poland. The meteorological station that we chose was situated about $4 \mathrm{~km}$ from a manufacturer of ready-mixed concrete, and about $7 \mathrm{~km}$ from the actual construction site. We completed the temperature and rainfall data using widely available resources of the National Research Institute [31]. We unified the average daily air temperatures for each meteorological station by calculating daily means value using (T06 + T18 + TMAX + TMIN)/4 (see, e.g., [32]). Temperature T06 and T18 are the values of air temperature at 06:00 and 18:00 in UTC (Universal Time Coordinated), respectively. Temperatures TMAX and TMIN are measured from 18.00 on the day " $N$ " until 18.00 on " $N+1$ " in UTC. This method of average daily air temperature calculation is used in climatological stations of the Polish Institute of Meteorology and Water Management since 1996. In Figure 1, we present the average daily air temperature $\mathrm{T}$ and daily rainfall $\mathrm{R}$ in the considered period. 


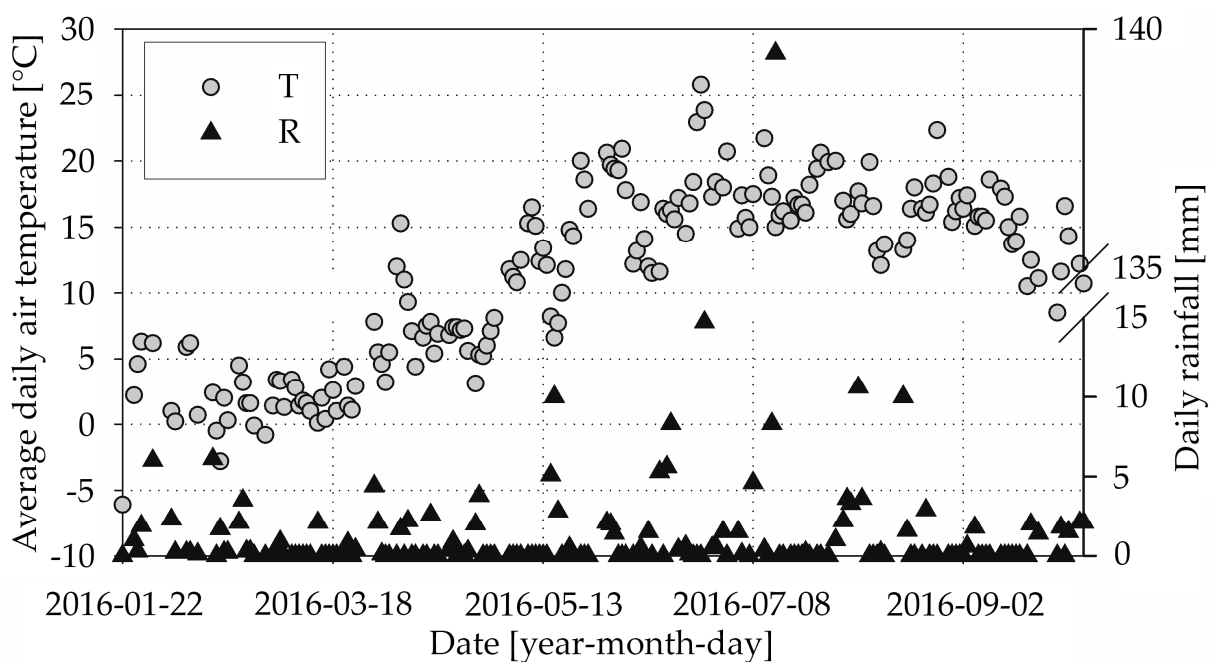

Figure 1. Average daily air temperature and daily rainfall in the investigated period.

In Table 3, we show the variability of investigated meteorological data: minimum, maximum, mean, and median. The difference between minimal and maximal average daily air temperature was equal to $31.9^{\circ} \mathrm{C}$. The median was equal to $+12.5^{\circ} \mathrm{C}$ and was insignificantly higher than the mean value of average daily air temperature. During the acquisition time, heavy rainfall and cloudburst occurred in Gdansk. The daily rainfall in 14 July 2016 was equal to $139.5 \mathrm{~mm}$ and the total rainfall in the studied period was $380.4 \mathrm{~mm}$. The mean daily rainfall without the maximal day rainfall on 14 July 2016 was equal to $1.31 \mathrm{~mm}$ only; see Table 3.

Table 3. Variability of investigated meteorological data in the studied period.

\begin{tabular}{ccccc}
\hline Meteorological Data & Min & Max & Mean & Median \\
\hline $\begin{array}{c}\text { Average daily air } \\
\text { temperature }\left[{ }^{\circ} \mathrm{C}\right]\end{array}$ & -6.1 & +25.8 & +11.35 & +12.50 \\
Daily rainfall $[\mathrm{mm}]$ & 0.0 & 139.5 & $2.08(1.31)^{1}$ & 0.0 \\
\hline \multicolumn{7}{c}{ Mean rainfall without maximal day of 14 July 2016. }
\end{tabular}

\subsection{Laboratory Tests}

The uniaxial compressive experimental laboratory tests were performed using a standard computer-operated testing machine (Advantest 9 C300KN) on standard cubical concrete samples with dimensions of $15 \times 15 \times 15 \mathrm{~cm}$. In accordance with EN 12390-3 [33], samples were loaded with a constant loading rate of $0.6 \mathrm{MPa} / \mathrm{s}$ to failure. We calculated the individual test result for compressive strength $f_{c i}(\mathrm{MPa})$ and daily mean compressive strength of concrete $f_{c m}(\mathrm{MPa})$ with the equation:

$$
f_{c i}=\frac{F_{i}}{A_{c i}}, \quad f_{c m}=\sum_{n=1}^{n} f_{c i} / n,
$$

where $F_{i}$ is a maximum load at failure, $A_{\mathrm{ci}}$ is a cross-sectional area of the specimen, and $n$ is the number of samples ( $n=3$ or 4$)$. The daily mean compressive strength of concrete was calculated for each investigated concrete mix type used on that day on the building site; see Table 2.

In Figure 2a, Figure 3a, Figure 4a, respectively, we presented the mean daily compressive strength of concrete from the laboratory tests and the corresponding average daily air temperatures. It can be seen that there is an effect of average daily air temperature on mean compressive strength for concrete mix CM_A type (Figure 2a), which we elaborate on in the discussion section. In Figure 2b, Figure 3b, Figure $4 \mathrm{~b}$, respectively, we show the mean daily compressive strength and corresponding daily rainfall. The influence of rainfall on the mean daily compressive strength is not apparent. Nevertheless, there 
are cases wherein the producer, due to the lack of proper protection of the aggregate against the effects of rainfall precipitation, uses an aggregate that does not meet the appropriate parameters-e.g., excessive moisture or irrigated-for the production of concrete mix. A change in the amount of water in the concrete mix will result in a reduction in mechanical properties, including the compressive strength of the concrete. Such cases are sporadic and are related to the lack of proper quality control by the manufacturer of the concrete mix.

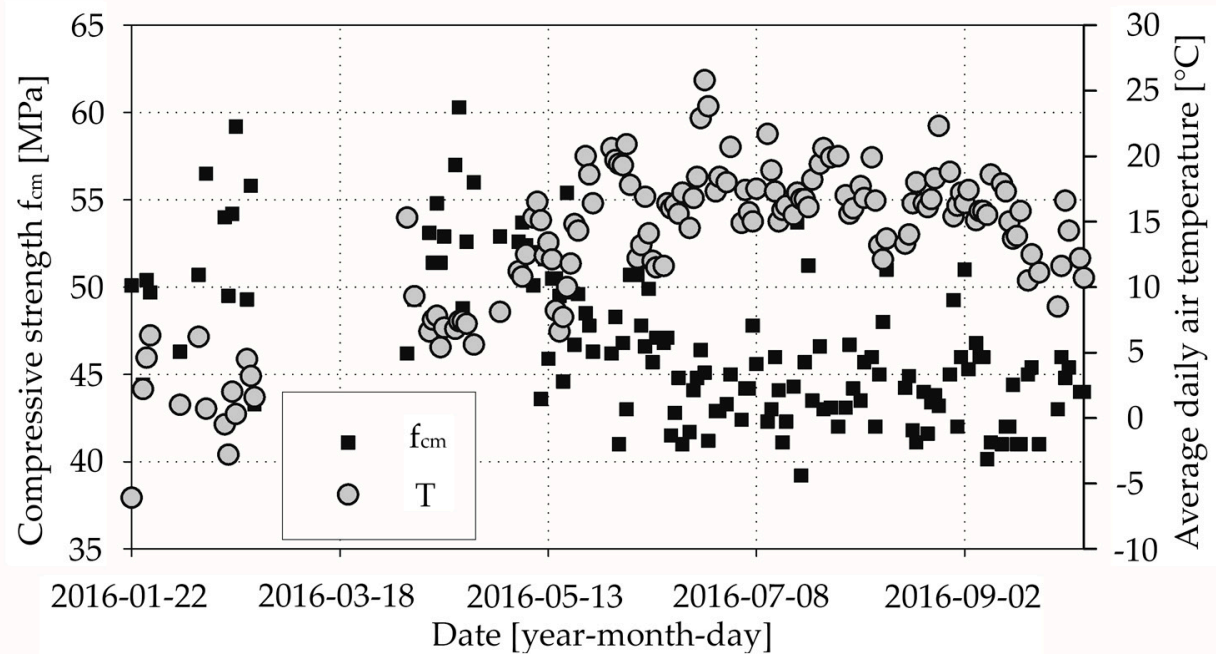

(a)

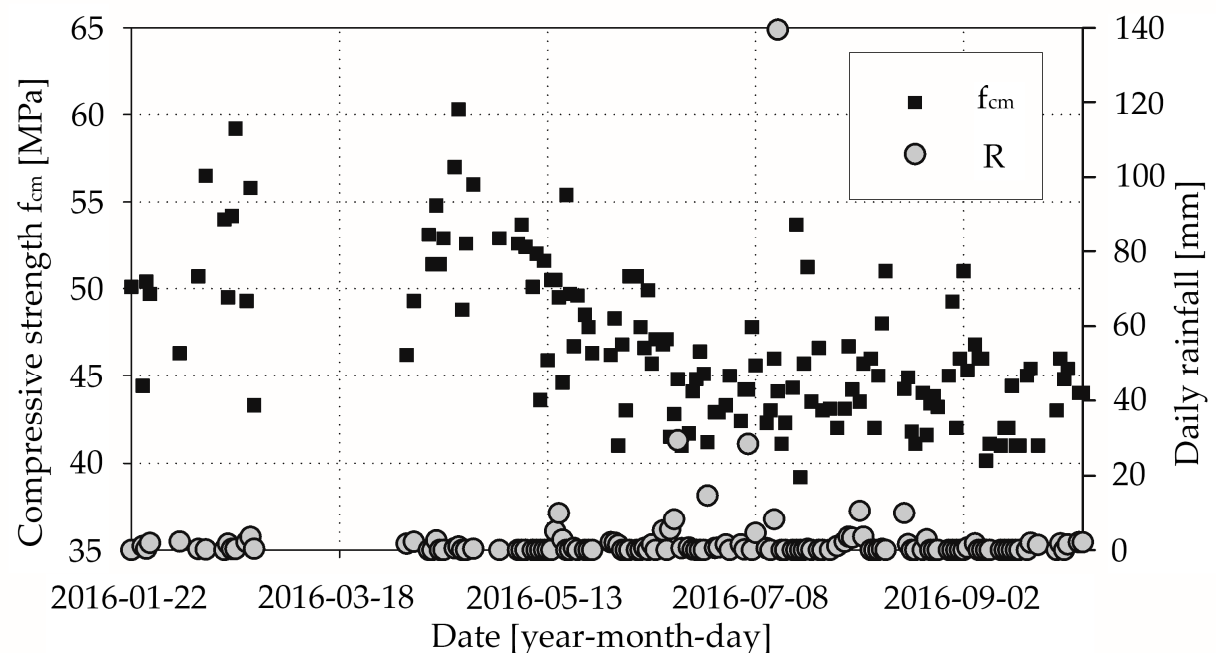

Figure 2. Laboratory test results for concrete mix CM_A type: (a) compressive strength and corresponding average daily air temperatures; (b) compressive strength and corresponding daily rainfall. 


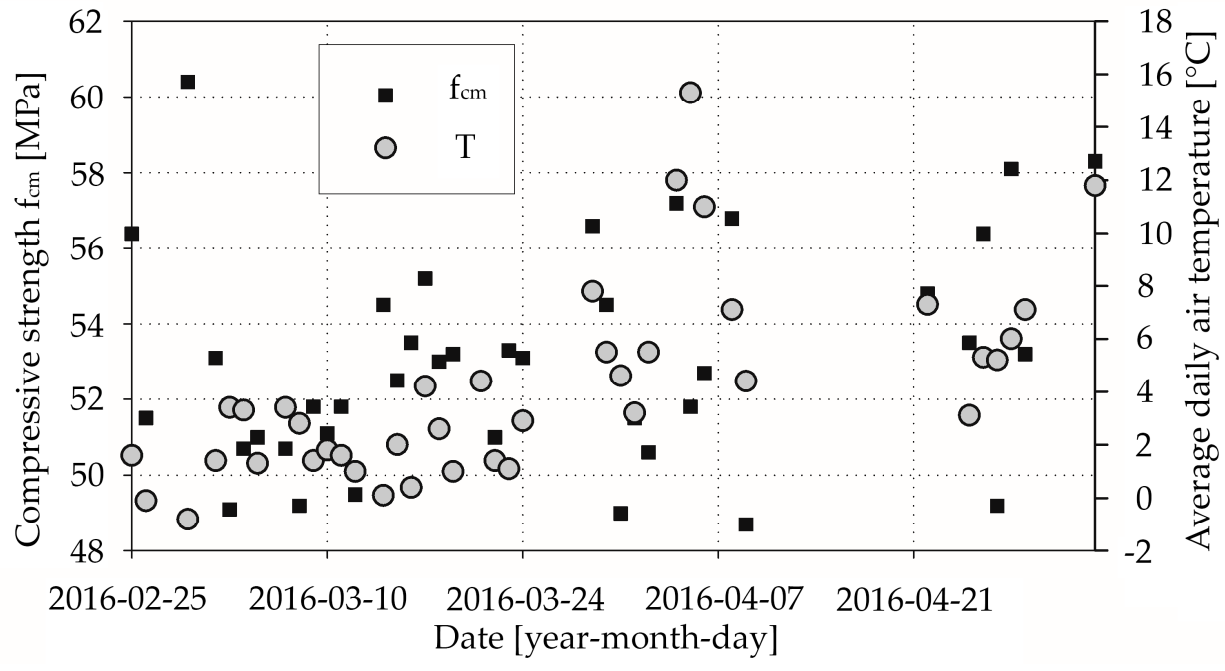

(a)

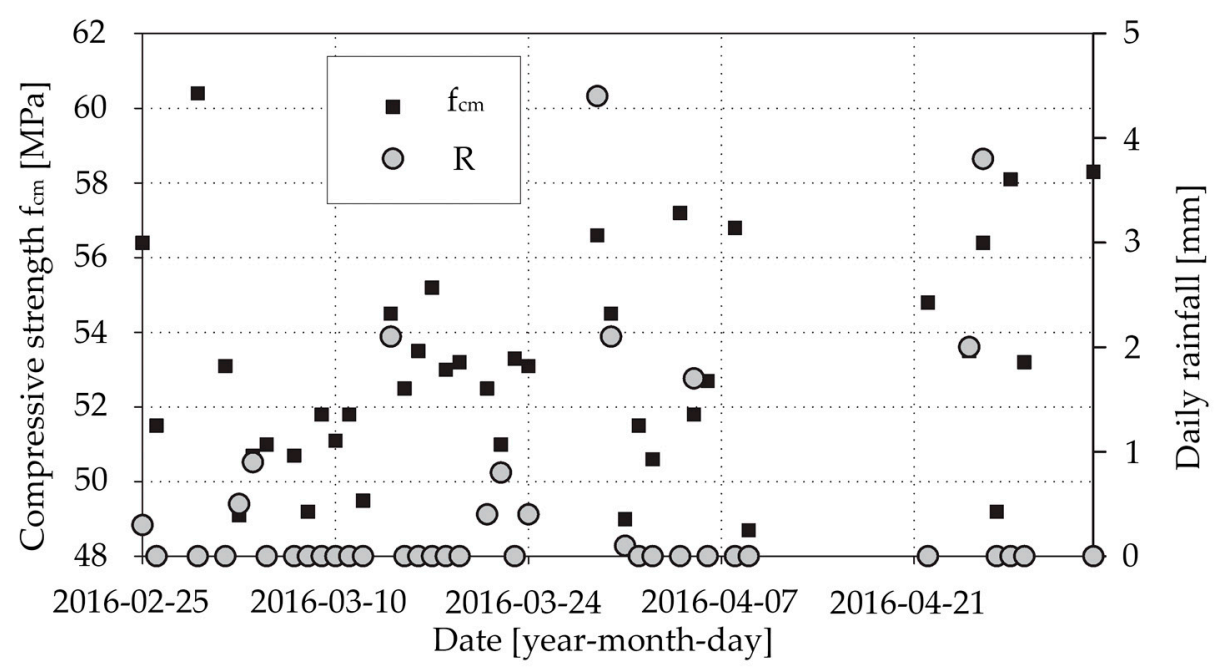

Figure 3. Laboratory test results for concrete mix CM_Aw type: (a) compressive strength and corresponding average daily air temperatures; (b) compressive strength and corresponding daily rainfall.

In Table 4, we present basic statistics for compressive strength values of samples from the considered concrete mixes. Table 4 is populated by minimum and maximum values (min and max), means, medians, standard deviations (stddev), and coefficient of variation (CV). The calculations were performed in two ways. Firstly, the statistical values refer to daily means of compressive strength, and secondly, they refer to the total number of concrete specimens; see Table 2. The differences between maximal and minimal values of daily means $f_{c m}$ are significant and vary over $11.7 \mathrm{MPa}$ for CM_B mix and 21.1 MPa for CM_A mix, and they are reflected in standard deviation values. The differences between maximal and minimal values specified from the total number of concrete specimens are higher and vary over 24.5 MPa for CM_B mix and 30.5 MPa for CM_A mix. The difference between mean and median values of daily means is tiny for CM_Aw $(0.17 \mathrm{MPa})$ and CM_B $(0.29 \mathrm{MPa})$ mixes and small for CM_A (0.9 MPa). Likewise, the difference between mean and median values of total specimens is tiny for CM_Aw (0.20 MPa) and CM_B (0.26 MPa) mixes and small for CM_A (1.02 MPa). The coefficient of variation $(\mathrm{CV})$ is calculated as the ratio of the standard deviation to the mean and is a statistical measure of the distribution of data around the mean. It can be shown that the dispersion is lower for the CM_Aw and CM_B concrete mixes than for the CM_A mix. 


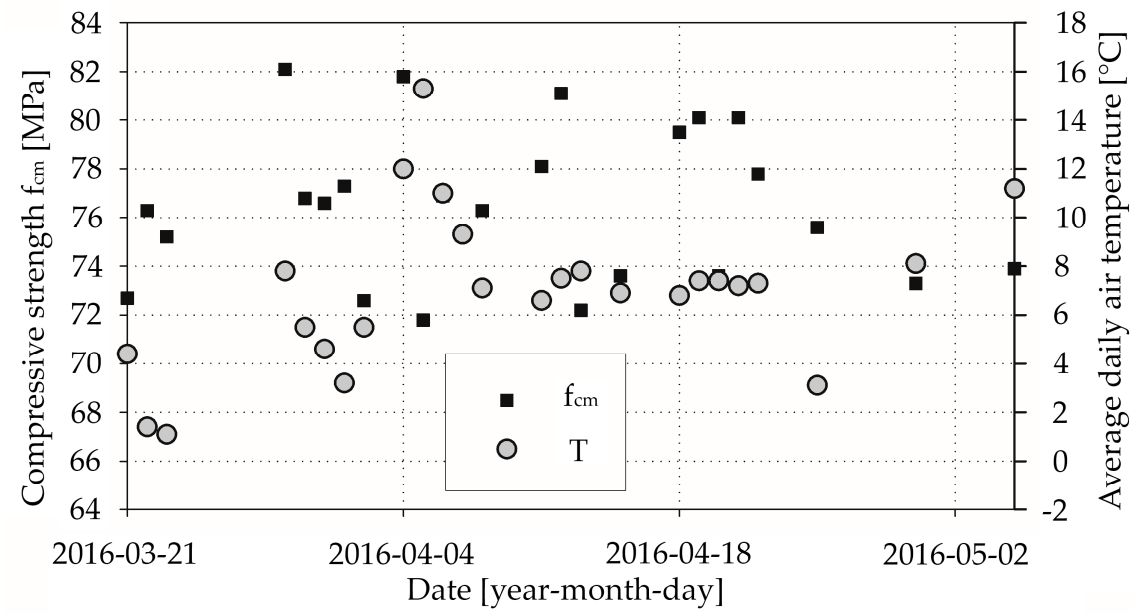

(a)

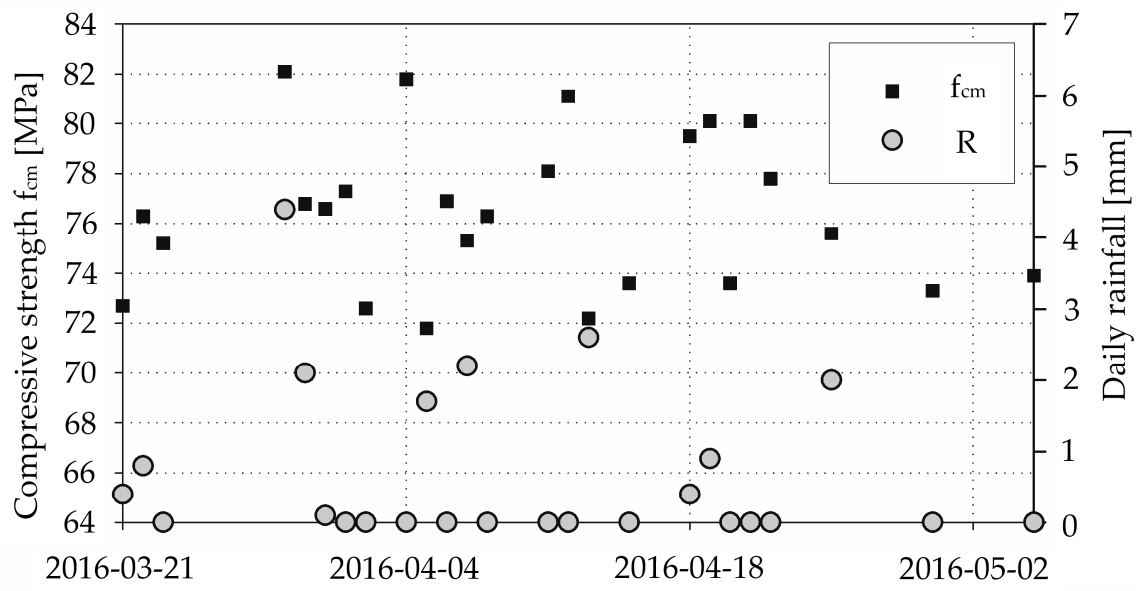

(b)

Date [year-month-day]

Figure 4. Laboratory test results for concrete mix CM_B type: (a) compressive strength and corresponding average daily air temperatures; (b) compressive strength and corresponding daily rainfall.

Table 4. Compressive strength of concrete mix type.

\begin{tabular}{cccccccc}
\hline $\begin{array}{c}\text { Concrete } \\
\text { Mix Type }\end{array}$ & Specimens Number & $\begin{array}{c}\text { Min } \\
{[\mathbf{M P a}]}\end{array}$ & $\begin{array}{c}\text { Max } \\
{[\mathbf{M P a}]}\end{array}$ & $\begin{array}{c}\text { Mean } \\
{[\mathbf{M P a}]}\end{array}$ & $\begin{array}{c}\text { Stddev } \\
{[\mathbf{M P a}]}\end{array}$ & $\begin{array}{c}\text { CV } \\
{[-]}\end{array}$ & $\begin{array}{c}\text { Median } \\
{[\mathbf{M P a}]}\end{array}$ \\
\hline \multirow{2}{*}{ CM_A } & 141 daily means & 39.2 & 60.3 & 46.60 & 4.36 & 0.09 & 45.70 \\
& 482 concrete specimens & 35.1 & 65.6 & 46.82 & 4.68 & 0.10 & 45.80 \\
CM_Aw & 40 daily means & 48.7 & 60.4 & 53.02 & 2.85 & 0.05 & 52.85 \\
& 152 concrete specimens & 46.6 & 61.6 & 53.10 & 3.42 & 0.06 & 53.30 \\
CM_B & 50 daily means & 64.7 & 82.1 & 74.44 & 3.96 & 0.05 & 74.15 \\
& 152 concrete specimens & 63.4 & 87.9 & 74.36 & 4.83 & 0.06 & 74.10 \\
\hline
\end{tabular}

Conformity of compressive strength was assessed on specimens with full concrete compressive strength (after 28 days) following EN 206-1 standard [24] for concrete without production control certification:

- The mean strength of non-overlapping consecutive results $f_{c m} \geq f_{c k}+4$ (criterion 1 );

- $\quad$ Each test result $f_{c i} \geq f_{c k}-4$ (criterion 2);

and concrete with production control certification:

- $\quad$ mean of three or four results for a single-family member $f_{c m} \geq f_{c k}+1$ or $f_{c m} \geq f_{c k}+2$ (criterion 3 ). 
The second criterion satisfied each test results for all tested specimens. In Figure 5, we show an illustration of criterion 1 for respective concrete grades. It can be seen that in the building construction, built-in concrete is characterised by compressive strength two or even three classes higher than in the design. In Table 5, we present the conformity criterion results for compressive strength in reference to daily means of compressive strength; see Table 2.

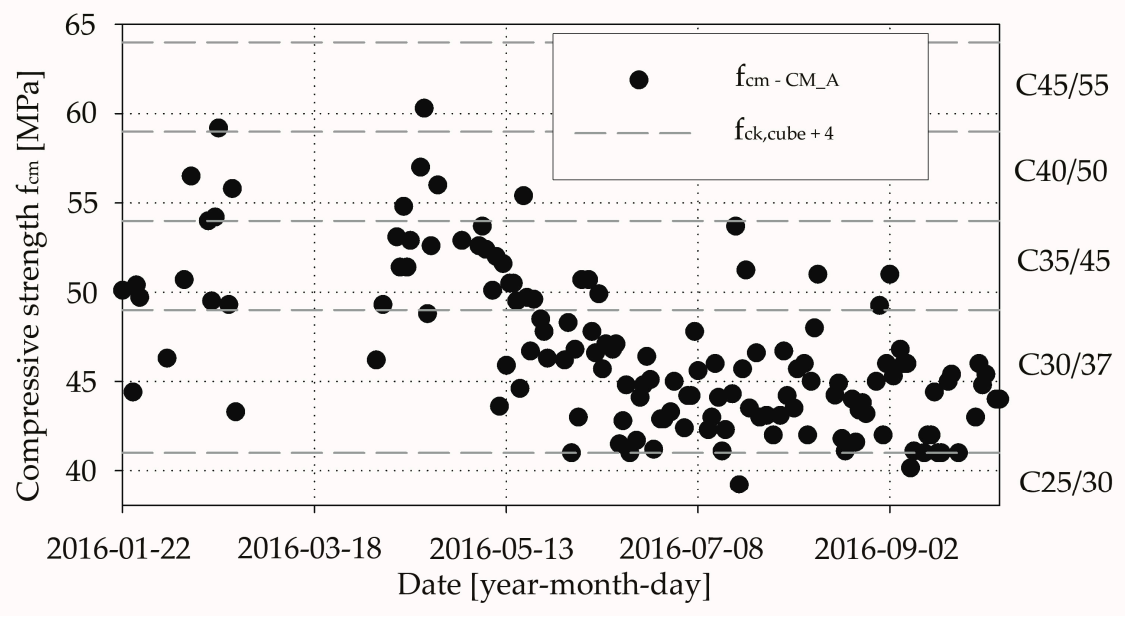

(a)

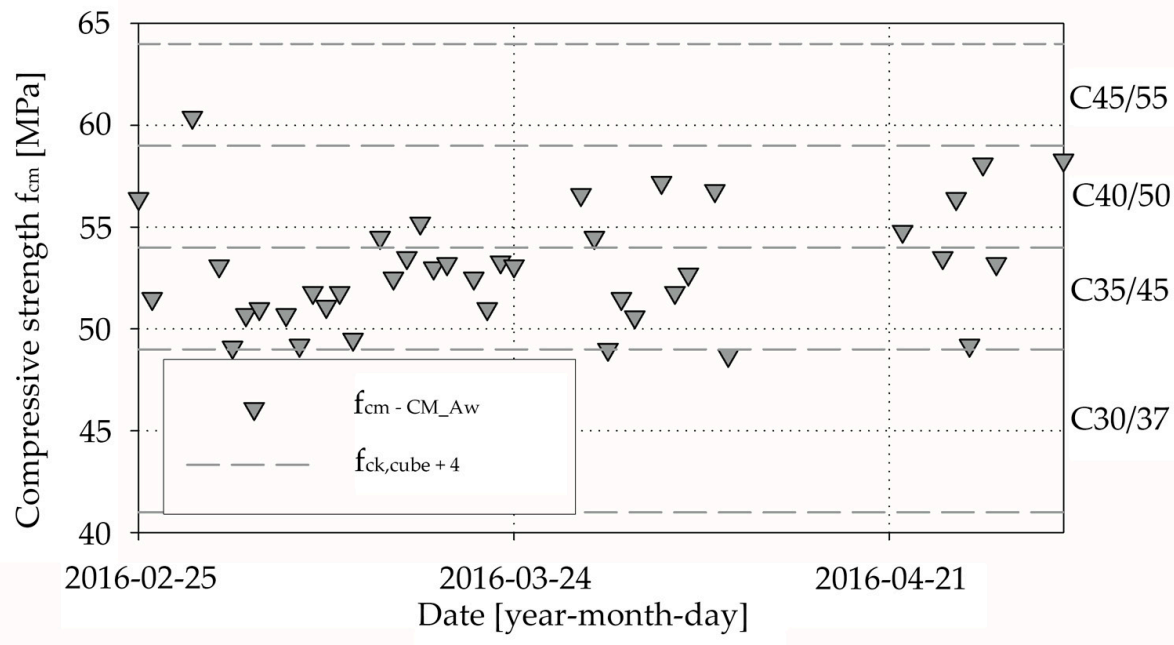

(b)

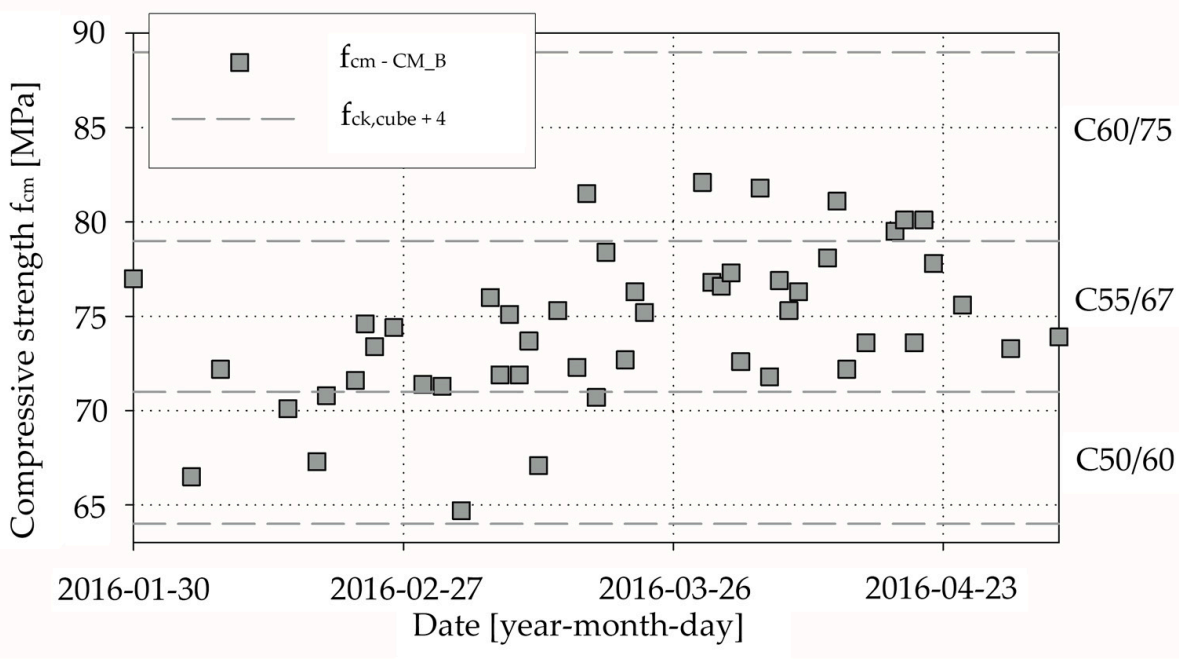

Figure 5. Criterion 1 for compressive strength classes conditions: (a) CM_A mix; (b) CM_Aw mix; (c) CM_B mix. 
Table 5. Conformity criterion results for concrete mix type.

\begin{tabular}{|c|c|c|c|c|c|c|}
\hline \multirow{2}{*}{ Concrete Mix Type } & \multicolumn{2}{|c|}{ CM_A } & \multicolumn{2}{|c|}{ CM_Aw } & \multicolumn{2}{|c|}{ CM_B } \\
\hline & Criterion 3 & Criterion 1 & Criterion 3 & Criterion 1 & Criterion 3 & Criterion 1 \\
\hline $\mathrm{C} 25 / 30$ & $0(0 \%)$ & $2(1.4 \%)$ & $0(0 \%)$ & $0(0 \%)$ & - & - \\
\hline $\mathrm{C} 30 / 37$ & $72(51.1 \%)$ & $97(68.8 \%)$ & $0(0 \%)$ & $1(2.5 \%)$ & - & - \\
\hline C $35 / 45$ & $44(31.2 \%)$ & $32(22.7 \%)$ & $9(22.5 \%)$ & $27(67.5 \%)$ & - & - \\
\hline $\mathrm{C} 40 / 50$ & $20(14.2 \%)$ & $8(5.7 \%)$ & $23(57.5 \%)$ & $11(27.5 \%)$ & - & - \\
\hline $\mathrm{C} 45 / 55$ & $5(3.5 \%)$ & $2(1.4 \%)$ & $8(20 \%)$ & $1(2.5 \%)$ & $0(0 \%)$ & $0(0 \%)$ \\
\hline C50/60 & - & - & - & - & $4(8 \%)$ & $7(14 \%)$ \\
\hline C55/67 & - & - & - & - & $28(56 \%)$ & $36(72 \%)$ \\
\hline C60/75 & - & - & - & - & $18(36 \%)$ & 7 (14\%) \\
\hline Total sum & \multicolumn{2}{|c|}{$141(100 \%)$} & \multicolumn{2}{|c|}{40 (100\%) } & \multicolumn{2}{|c|}{$50(100 \%)$} \\
\hline
\end{tabular}

For the CM_A concrete mix, about $69 \%$ in criterion 1 and $51 \%$ in criterion 3 test results can be assigned to C30/37 concrete grade. Nearly $30 \%$ in criterion 1 and $49 \%$ in criterion 3 of the daily mean compressive strength values of concrete can be assigned to higher concrete grade, and only $1.4 \%$ in criterion 1 did not achieve the designed compressive strength. In the case of CM_Aw concrete mix, only $2.5 \%$ in criterion 1 of test results can be directly assigned to C30/37 concrete grade. The vast majority in criterion $1(97.5 \%)$ and all in criterion 3 of the daily mean compressive strength values were classified as higher concrete grades. There were similarities in the case of CM_B concrete mix samples, where we also observed that a significant number ( $86 \%$ in criterion 1 and $92 \%$ in criterion 3 ) of daily mean compressive strength readings exceeding the range of concrete grade expected.

\section{Results and Discussion}

In the results of our study, we observed the influence of average daily temperature on mean compressive strength (Figure 2a). For the considered case of concrete mix type CM_A, we found out that in a time when the average daily air temperature was from $+5^{\circ} \mathrm{C}$ to $+10^{\circ} \mathrm{C}$, the compressive strength of concrete increased; on the other hand, when the average daily air temperature reached over $+10^{\circ} \mathrm{C}$ the compressive strength of concrete was decreasing, as we can see in Figure 2a. We think that faster hydration of the cement at higher temperatures in the course of the technological process forged weak concrete microstructurally, due to a disrupted hydration pattern and higher porosity, so that some of the pores could never be filled [34]. The study of Lothenbach et al. seems to support that conclusion partially [35].

Most of our results from concrete mix type CM_A (about $67 \%$ in criterion 1 and $51 \%$ in criterion 3 , as we described in Section 2.4) were assigned to class C30/37. However, almost all of the remaining samples can be attributed to the higher compressive strength class (30\% in criterion 1 and $49 \%$ in criterion $3 ; 1.4 \%$ in criterion 1 had lower compressive strength), which raises a significant problem. In the theory of limit states, a recipe has to be rejected if the set of minimum results exceeds $5 \%$. For the CM_Aw concrete mix, merely $2.5 \%$ in criterion 1 of test results can be designated as C30/37 concrete grade. A large majority in criterion 1 (97.5\%) and all in criterion 3 of the daily mean compressive strength values were classified to higher compressive class. Application of accelerating hardening admixture in the CM_Aw concrete mix caused not only achieving high early strength but also higher compressive strength classes, which can be connected with the absorption of superplasticiser. According to G. Cygan et al. [11], increased temperature led to the loss of workability and sped up the hydration process, but simultaneously, a more considerable amount of ettringite was produced, which adsorbs superplasticisers. That is why hardening might be inhibited, which results in achieving not only high early compressive strength but also higher full compressive strength. From a concrete manufacturer's point of view, this phenomenon is beneficial because according to the EN-206 standard [24], he has to guarantee the specific compressive strength of the concrete grade. We observed the same pattern for the CM_B concrete mix ( $86 \%$ in criterion 1 and $92 \%$ in criterion 3 ). When it comes to precipitation, we did not notice a significant correlation between the obtained compressive strength and daily rainfall. 
The investigated concrete mixes may have exhibited excessive compressive strength beyond that designed for the concrete grade. We took into account the aforementioned 5 MPa surplus of concrete compressive strength and calculated the upper limit of compressive strength ULCS for investigated concrete mixes; see Table 6.

Table 6. The upper limit for "concrete superstrength."

\begin{tabular}{cccc}
\hline Concrete Mix Type & $f=f_{c k}+\mathbf{5}[\mathrm{MPa}]$ & $f+\mathbf{1 . 9 6} \cdot \sigma[\mathrm{MPa}]$ & $\mathbf{1 . 2 5} \cdot(f+\mathbf{1 . 9 6} \cdot \sigma)[\mathrm{MPa}]$ \\
\hline CM_A & 42.0 & 52.6 & 65.7 \\
CM_Aw & 65.0 & 75.6 & 94.5 \\
CM_B & & & \\
\hline
\end{tabular}

For concrete grades C30/37 and C50/60, ULCS was equal to 65.7 and $94.5 \mathrm{MPa}$, respectively. We can assume that the ULCS can be considered as the maximal value of $f_{c m}$, which we specified in Table 4 . We conclude that the compressive strength of the concrete did not exceed more than $25 \%$ of the designed one for considered concrete grades. For such a limitation assumed in the evaluation, the concrete mixes did not exhibit attributes of concrete superstrength. Nevertheless, some specifications for ready-mixed concrete breach the other restricted upper limits of compressive strength. In each case, the concrete mixes used should be separately analysed and assessed in terms of meeting the requirements.

\section{Summary and Conclusions}

Concrete production and the forging of concrete structures are complex and multistage processes. There are many factors that can affect the final performance of the obtained structure. Environmental conditions present during concrete production seems to be a prominent factor, although this feature is rarely considered, except in extreme cases of negative temperatures during the winter. In our research, we decided to deal with this topic and find out the answer to how environmental conditions during concrete production affect its performance. We studied the influences of temperature and precipitation on concrete performance, considering several parameters such as composition and features of concrete mix, the average compressive strength of concrete, average daily air temperature, and daily rainfall. The concrete that we tested was both produced and transported to a construction site located in Gdansk, Poland. We examined three types of concrete mixes as follows: CM_A, CM_Aw, and CM_B. All of them are based on CEM I (Portland cement; see EN 197-1 standard [25] and [26]) and they had the following concrete grades, according to EN 206 standard [24]): C30/37 for two of them and C50/60 for the last one respectively. The fresh concrete mix produced by the manufacturer was subjected to uniaxial compression laboratory tests to determine the concrete compressive strength, after reaching the 28th day period. Concrete samples were standard cubical samples with every dimension equal to $15 \mathrm{~cm}$, according to PN-EN 12390-2 [27] standard. We obtained meteorological data from the Gdansk-Rebiechowo station situated about $4 \mathrm{~km}$ from the concrete manufacturer and $7 \mathrm{~km}$ from the actual construction site, with the resources of the National Climate Data Center [30]. Within our research, we sought a connection between average daily air temperature, daily rainfall, and compressive strength. We determined that while the average daily air temperature was over $+10^{\circ} \mathrm{C}$, the compressive strength decreased in comparison to when the average daily air temperature was between $+5^{\circ} \mathrm{C}$ and $+10^{\circ} \mathrm{C}$. This could be due to the higher pace of hydration of cement in higher temperatures, which creates a weak concrete microstructure. We did not notice a significant correlation between the daily rainfall and compressive strength. Therefore, we believe that it is safe to state that rainfall does not significantly affect the technological process of producing and transporting the concrete mix if it does not exceed the average values for a given region. Note that this can only be applied to a warm temperate, transitional climate with the influences of maritime and continental climates, such as occurs in central-eastern Europe.

The concrete mixes that we examined also showed excessive compressive strength beyond the designed concrete grade. That can raise a fundamental problem. Material that has a compressive 
strength higher than the designed one also has different stiffness, which is not beneficial from a structural point of view. Excessive stiffness of some parts of structural elements may cause a different redistribution of internal forces, so that elements with higher stiffness may exhibit greater than assumed stress and deformation. Uncontrolled cracks may appear at the joints of structural elements, which are supposed to be uniform in terms of strength and made of concrete with specific material properties. It would be valuable to explore this topic more by merging analytical finite element method modelling of buildings or civil engineering structures and varying material features within individual elements of the construction, supported by according laboratory tests. Comparison of the static-strength analysis, backed by experimental data and actual design state would allow us to estimate the impact of the high variability of concrete mechanical properties within the structure. We plan to undertake this topic in our future research.

The conformity criterion for the specification of concrete grade only determines requirements for minimal compressive strength. In the European Union, the current norm for ready mixed concrete is EN 206 [24], which is not a harmonised standard (hEN). The ready-mixed concrete also does not carry a CE (Conformité Européenne) mark. Aggregates and precast concrete products are usually covered by harmonised standards, such as the Construction Products Regulation (CPR; see [36]). However, some manufacturers of ready-mixed concrete decide to implement the voluntary certification process to be able to take advantage of the provisions proposed by EN-206 standard [24] in terms of reducing the frequency of tests and less conservative criteria of identity (e.g., application of criterion 3). Details of the tasks of the unit involved in the production control certification process are provided in standard EN 206 [24] Annex C "Provisions for assessment, surveillance and certification of production control." Moreover, some design specifications request a certification process of ready-mixed concrete according to the EN-206 standard [24]. A lack of certification means that the concrete mix producer might be excluded from supplying concrete to the construction site. In some EU Member States from 31 November 2020 (the date was delayed from 30 June 2018) the ready-mixed concrete will be included into groups of construction products for which a national declaration of performance should be drawn up, and national systems of assessment and verification should be introduced according to the regulation [37]. In this case, the certification process of ready-mixed concrete is obligatory.

The results we obtained encourage us to continue the research and might be a base for numerous new investigations. In our future research, we plan to expand the database of measured parameters through new laboratory tests, especially those related to cement hydration and heat of hydration changes. We also plan to supplement our study with numerical analyses and field measurements of a built concrete structure to estimate an influence of material variability expressed by excessive compressive strength beyond the designed concrete grade. We hope that our findings spark a vital interest in the community of scientists and civil engineers to take into consideration the influences of environmental conditions during the manufacture of concrete on its mechanical behaviour.

Author Contributions: Conceptualisation, A.A. and P.Z.; data curation, A.A.; formal analysis, A.A. and P.Z.; funding acquisition, A.A. and P.Z.; investigation, A.A.; methodology, A.A. and P.Z.; project administration, A.A. and P.Z.; resources, A.A.; Software, A.A. and P.Z.; supervision, A.A. and P.Z.; validation, A.A. and P.Z.; visualization, A.A. and P.Z.; writing—original draft, A.A. and P.Z; writing—review and editing, A.A. and P.Z. All authors have read and agreed to the published version of the manuscript.

Funding: This research received no external funding.

Acknowledgments: The author wishes to acknowledge every institution which provided data and tools to conduct this study.

Conflicts of Interest: The authors declare no conflict of interest.

\section{References}

1. CEN. EN 1992-1-1. Eurocode 2: Design of Concrete Structures-Part 1-1: General Rules and Rules for Buildings; CEN: Brussels, Belgium, 2004. 
2. ACI. ACI 318-19. Building Code Requirements for Structural Concrete; ACI: Farmington Hills, MI, USA, 2019. [CrossRef]

3. Kurpinska, M.; Grzyl, B.; Pszczola, M.; Kristowski, A. The application of granulated expanded glass aggregate with cement grout as an alternative solution for sub-grade and frost-protection sub-base layer in road construction. Materials 2019, 12, 3528. [CrossRef] [PubMed]

4. Kaszynska, M.; Nowak, A.S. Effect of Material Quality on Life-Time Performance of Concrete Structures. Life-Cycle Performance of Deteriorating Structures; Routledge: Abingdon, UK, 2003; pp. 141-147. [CrossRef]

5. Trawiński, W.; Tejchman, J.; Bobiński, J. A three-dimensional meso-scale approach with cohesive elements to concrete fracture based on X-ray $\mu \mathrm{CT}$ images. Eng. Fract. Mech. 2018, 189, 27-50. [CrossRef]

6. Skarżyński, L.; Tejchman, J. Experimental investigations of damage evolution in concrete during bending by continuous micro-CT scanning. Mater. Charact. 2019, 154, 40-52. [CrossRef]

7. Ambroziak, A.; Haustein, E.; Kondrat, J. Chemical and mechanical properties of 70-year-old concrete. J. Mater. Civ. Eng. 2019, 31, 4019159. [CrossRef]

8. CEN. EN 13670. Execution of Concrete Structures; CEN: Brussels, Belgium, 2009.

9. Ziolkowski, P.; Niedostatkiewicz, M. Machine learning techniques in concrete mix design. Materials 2019, 12, 1256. [CrossRef]

10. Abdelgader, H.S.; Suleiman, R.E.; El-Baden, A.S.; Fahema, A.H.; Angelescu, N. Concrete mix proportioning using three equations method (Laboratory Study). In Proceedings of the UKIERI Concrete Congress Innovations in Concrete Construction, Jalandhar, Punjab, India, 5-8 March 2013.

11. Abdelgader, H.S.; Saud, A.F.; Othman, A.M.; Fahema, A.H.; El-Baden, A.S. Concrete mix design using the double-coating method. Betonw. Fert. Plant Precast. Technol. 2014, 80, 66-74.

12. Abdelgader, H.S.; Fediuk, R.S.; Kurpinska, M.; Khatib, J.; Murali, G.; Baranov, A.V.; Timokhin, R.A. Mechanical properties of two-stage concrete modified by silica fume. Mag. Civ. Eng. 2019, 89, 26-38. [CrossRef]

13. Tran, Q.H.; Han, D.; Kang, C.; Haldar, A.; Huh, J. Effects of ambient temperature and relative humidity on subsurface defect detection in concrete structures by active thermal imaging. Sensors 2017, 17, 1718. [CrossRef]

14. Chen, D.; Zou, J.; Zhao, L.; Xu, S.; Xiang, T.; Liu, C. Degradation of dynamic elastic modulus of concrete under periodic temperature-humidity action. Materials 2020, 13, 611. [CrossRef]

15. Bai, Y.; Wang, Y.; Xi, Y. Modeling the effect of temperature gradient on moisture and ionic transport in concrete. Cem. Concr. Compos. 2020, 106, 926. [CrossRef]

16. Price, W.H. Factors influencing concrete strength. ACI J. Proc. 1951, 47, 417-432. [CrossRef]

17. Escalante-Garcia, J.I.; Sharp, J.H. Effect of temperature on the hydration of the main clinker phases in Portland cements: Part I, neat cements. Cem. Concr. Res. 1998, 28, 1245-1257. [CrossRef]

18. Escalante-Garcia, J.I.; Sharp, J.H. Effect of temperature on the hydration of the main clinker phases in Portland cements: Part II, blended cements. Cem. Concr. Res. 1998, 28, 1259-1274. [CrossRef]

19. Escalante-García, J.I.; Sharp, J.H. The microstructure and mechanical properties of blended cements hydrated at various temperatures. Cem. Concr. Res. 2001, 31, 695-702. [CrossRef]

20. Komonen, J.; Penttala, V. Effects of high temperature on the pore structure and strength of plain and polypropylene fiber reinforced cement pastes. Fire Technol. 2003, 39, 23-34. [CrossRef]

21. Thomas, J.J.; Rothstein, D.; Jennings, H.M.; Christensen, B.J. Effect of hydration temperature on the solubility behavior of Ca-, S-, Al-, and Si-bearing solid phases in Portland cement pastes. Cem. Concr. Res. 2003, 33, 2037-2047. [CrossRef]

22. Soudki, K.A.; El-Salakawy, E.F.; Elkum, N.B. Full factorial of optimisation of concrete mix design for hot climates. J. Mater. Civ. Eng. 2001, 13, 427-433. [CrossRef]

23. Cygan, G.; Gołaszewski, J.; Drewniok, M. The effect of temperature on the properties of fresh self-compacting concrete. Arch. Civ. Eng. 2016, 62, 23-32. [CrossRef]

24. CEN. EN 206:2013+A1:2016. Concrete—Specification, Performance, Production and Conformity; CEN: Brussels, Belgium, 2016.

25. CEN. EN 197-1. Cement_Part 1: Composition, Specifications and Conformity Criteria for Common Cements; CEN: Brussels, Belgium, 2000.

26. Müller, C. Use of cement in concrete according to European standard EN 206-1. HBRC J. 2012, 8, 1-7. [CrossRef] 
27. PKN. PN-EN 12390-2. Testing Hardened Concrete-Part 2: Making and Curing Specimens for Strength Tests; Polish Committee for Standardization: Warsaw, Poland, 2019.

28. Kepniak, M.; Woyciechowski, P. The statistical analysis of relation between compressive and tensile/flexural strength of high performance concrete. Arch. Civ. Eng. 2016, 62, 95-107. [CrossRef]

29. Jasiczak, J. "Concrete postlimiting behaviour" concept in tendering procedure for concrete facilities of communications infrastructure. Bud. Technol. Archit. 2017, 1, 64-68.

30. Kepinska-Kasprzak, M.; Struzik, P. Agrometeorological service provided by Institute of Meteorology and Water Management-National Research Institute. Biol. Rhythm Res. 2019, 50, 327-334. [CrossRef]

31. Public Data of IMWM-PIB. Available online: https://danepubliczne.imgw.pl/datastore (accessed on 13 October 2020).

32. Szymanowski, M.; Kryza, M.; Spallek, W. Regression-based air temperature spatial prediction models: An example from Poland. Meteorol. Z. 2013, 22, 577-585. [CrossRef]

33. CEN. EN 12390-3. Testing Hardened Concrete. Compressive Strength of Test Specimens; CEN: Brussels, Belgium, 2019.

34. Neville, A. Properties of Concrete, 4th ed.; Wiley: Hoboken, NJ, USA, 1996.

35. Lothenbach, B.; Winnefeld, F.; Alder, C.; Wieland, E.; Lunk, P. Effect of temperature on the pore solution, microstructure and hydration products of Portland cement pastes. Cem. Concr. Res. 2007, 37, 483-491. [CrossRef]

36. Regulation (EU). No 305/2011 of The European Parliament and of The Council of 9 March 2011. Off. J. Eur. Union 2011, L 88, 5-43. Available online: https://eur-lex.europa.eu/eli/reg/2011/305/oj (accessed on 14 October 2020).

37. Regulation of the Minister of Infrastructure and Construction of 17 November 2016 on the Method of Declaring the Performance of Construction Products and the Method of Marking Them with a Construction Mark. 2016. Available online: http://isap.sejm.gov.pl/isap.nsf/DocDetails.xsp?id=WDU20160001966 (accessed on 14 October 2020).

Publisher's Note: MDPI stays neutral with regard to jurisdictional claims in published maps and institutional affiliations.

(C) 2020 by the authors. Licensee MDPI, Basel, Switzerland. This article is an open access article distributed under the terms and conditions of the Creative Commons Attribution (CC BY) license (http://creativecommons.org/licenses/by/4.0/). 